\title{
Differential hepatic stem cell proliferation and differentiation after partial hepatectomy in rats
}

\author{
PENG GONG, YINGXIN WANG, JING ZHANG and ZHONGYU WANG \\ Hepatobiliary Surgery, The First Affiliated Hospital of Dalian Medical University, \\ Dalian, Liaoning 110001, P.R. China
}

Received February 2, 2013; Accepted June 24, 2013

DOI: $10.3892 / \mathrm{mmr} .2013 .1606$

\begin{abstract}
Stem cell-derived hepatocyte precursor cells represent a promising model for clinical transplantation to diseased livers, as well as for establishment of in vitro systems for drug metabolism and toxicology studies. The present study aimed to establish a new method of induction of hepatocyte differentiation using various factors and evaluate the effect of different partial hepatectomies and the duration of collagenase perfusion on hepatic stem cell proliferation and differentiation. A rat model of hepatic oval cell proliferation was established by partial hepatectomy (PH). Following 73.1 and $83.4 \% \mathrm{PH}$, rats underwent perfusion with IV collagenase for 10, 20 and $30 \mathrm{~min}$. Density gradient centrifugation was performed and cells in the supernatant were cultured in various combinations of factors to induce oval cells to differentiate into mature hepatocytes. Cells were characterized for hepatocyte marker expression by morphology, flow cytometry, immunofluorescence and western blot analysis. Hepatic oval cells isolated from rats at 7 and 14 days post-PH exhibited properties of hepatic stem/progenitor cells. Following culturing in RPMI-1640 medium with hepatocyte growth factor and fibroblast growth factor-4, the cells resembled primary human hepatocytes with regard to morphology and expression of the hepatocyte markers, cytokeratin 18 (CK-18) and $\alpha$-1-fetoprotein (AFP). Optimal differentiation of hepatic stem cells to CK-18- and AFP-positive cells was observed when stem cells isolated from $83.4 \% \mathrm{PH}$ rats (7 days following surgery) were perfused with IV collagenase for $20 \mathrm{~min}$. The results of this study provide novel insights into characteristics of rat hepatic stem cells.
\end{abstract}

\section{Introduction}

Hepatitis, cirrhosis, hepatoma and end-stage liver disease caused by multiple factors still lack effective treatment proto-

Correspondence to: Professor Peng Gong, Hepatobiliary Surgery, The First Affiliated Hospital of Dalian Medical University, 222 Zhongshan Road, Dalian, Liaoning 110001, P.R. China E-mail: gongpengdalian@163.com

Key words: stem cells, differentiation, proliferation, hepatocytes cols. Treatment of chronic liver disease had become a major problem for clinicians due to the poor efficacy of clinical treatments and high mortality. It has been reported that $\sim 10 \%$ of patients with liver disease succumb to their condition while waiting for liver sources each year (1). Liver transplantation is currently the only therapeutic option for patients with end-stage chronic liver disease and for severe acute liver failure. Due to limited donor availability, surgical injury, a higher incidence of surgical complications and the expensive cost of treatment, the development of liver transplantation has been restricted (2).

Recent studies have focused on methods to restore liver mass and function through cell transplantation. Stem cells are a promising source for liver repopulation following cell transplantation (3). Several studies have reported that the administration of in vitro expanded stem cells may promote liver regeneration $(4,5)$. In addition, hepatic stem cells have been identified in adult liver tissues $(6,7)$ and oval cells derived from rodent and human livers have been demonstrated to be hepatic stem cells (8-10). Hepatic stem cells may participate in liver regeneration and restoration during serious liver injury (11-14). Thus, studies on the proliferation and differentiation of these cells are extremely useful for elucidating the molecular mechanisms of liver development.

In the present study, partial hepatectomy (PH) was performed to activate hepatic oval cells in rat livers, and oval cells undergoing proliferation and differentiation were identified by analysis of specific morphological and phenotypical characteristics. We sought to optimize hepatic stem cell proliferation and differentiation in in vitro culture by comparing various conditions, including different percentage $\mathrm{PH}$ and duration of collagenase perfusion.

\section{Materials and methods}

Animals. Male Wistar rats (age, 8-10 weeks old; weight, 150-180 g) were purchased from the Laboratory Animal Center of Dalian Medical University and maintained on standard laboratory chow and daily cycles of alternating $12 \mathrm{~h}$ of light and dark.

PH model. All experiments were performed in accordance with the Principles of Laboratory Animal Care and approved by the Local Committee for Experimental Animal Research. 
PH (73.1 and 83.4\%) of rat livers was performed according to the procedure described previously $(15,16)$. Sham-operated control animals were treated in an identical manner with the omission of hepatectomy.

Hepatic stem cell isolation. At 0,7 and 14 days following $\mathrm{PH}$, rat liver cells were isolated by a two-step collagenase IV digestion method, as described previously (17). The liver was perfused via a cannula in the inferior vena cava with $250 \mathrm{ml}$ buffer [142 $\mathrm{mM} \mathrm{NaCl}, 6.7 \mathrm{mM} \mathrm{KC1}$ and $10 \mathrm{mM}$ HEPES (pH 7.4)] followed by $250 \mathrm{ml}$ buffer containing additional $5.7 \mathrm{mM} \mathrm{CaCl}{ }_{2}$ and $0.5 \mathrm{mg} / \mathrm{ml} \mathrm{IV} \mathrm{collagenase} \mathrm{(Sigma-Aldrich,}$ St. Louis, MO, USA) for 10,20 or $30 \mathrm{~min}$.

Hepatic stem cell culture and differentiation. Isolation and purification of oval cells were performed according to the protocol of Pack et al (18) with specific modifications. Briefly, the hepatocytes were dispersed and washed twice with cold $\mathrm{Ca}^{2+}$-free perfusion buffer and resuspended in RPMI-1640 medium (Gibco-BRL, Carlsbad, CA, USA) supplemented with 10\% FBS (Hyclone Laboratories, Inc., Logan, UT, USA), $5 \mathrm{ng} / \mathrm{ml} \mathrm{M}$-CSF, $0.4 \mathrm{ng} / \mathrm{ml}$ IL-3 and $140 \mu \mathrm{M} \beta$-mercaptoethanol (all PeproTech Inc., Rocky Hill, NJ, USA) to stimulate stem cell proliferation. Following a 6-day culture period, culture medium was replaced with RPMI-1640 medium containing $10 \% \mathrm{FBS}, 20 \mu \mathrm{g} / 1$ hepatocyte growth factor (HGF) and $10 \mu \mathrm{g} / \mathrm{l}$ fibroblast growth factor-4 (FGF-4; both PeproTech, Inc.) to stimulate stem cell differentiation. Cell growth was observed under a contrast phase microscope and recorded at days 0,7 and 14 . Viability was determined by trypan blue exclusion and only preparations with $>90 \%$ viability were used. Cell number was determined with a hemocytometer (Bio-Rad, Hercules, CA, USA).

Flow cytometric analysis. The presence of CD $34^{+}$Thy $-1^{+}$ cells was determined at 0,7 and 14 days after PH. Freshly isolated cells $\left(1 \times 10^{5}\right)$ were fixed in cold acetone for $8 \mathrm{~min}$ at $4^{\circ} \mathrm{C}$. Following centrifugation at $141 \mathrm{x}$ g for $5 \mathrm{~min}$ at $4^{\circ} \mathrm{C}$, pellets were suspended in $0.1 \mathrm{ml}$ PBS and incubated with anti-CD34 and Thy-1 (Santa Cruz Biotechnology, Inc., Santa Cruz, CA, USA) antibodies for $60 \mathrm{~min}$ at $37^{\circ} \mathrm{C}$. Centrifugation was performed at $141 \mathrm{x}$ g for $15 \mathrm{~min}$ and followed by extensive washes in PBS. Pellets were suspended in $0.1 \mathrm{ml}$ PBS in preparation for cell suspension. Binding of primary antibody was detected by phycoerythrin (PE)-labeled IgG (Dako, Carpinteria, CA, USA). Cells were assayed by flow cytometry (Becton Dickinson, San Jose, CA, USA) and data were analyzed using Cell-Quest software (Becton Dickinson). Replacement of primary antibody with PE-labeled IgG served as a negative control.

Immunofluorescence assay of oval cells. Immunofluorescence analysis of oval cells in culture was performed on days 0,7 and 14. Cells on glass slides were fixed in cold acetone for $5 \mathrm{~min}$, blocked with normal goat serum following extensive washes in PBS (pH 7.4) and incubated with primary antibodies including anti-cytokeratin-18 (CK-18) and $\alpha$-1-fetoprotein (AFP) at $4^{\circ} \mathrm{C}$ overnight. Following washing three times in PBS, cells were cultured with PE-labeled IgG for $30 \mathrm{~min}$ at $37^{\circ} \mathrm{C}$, washed three times again in PBS and observed microscopically for

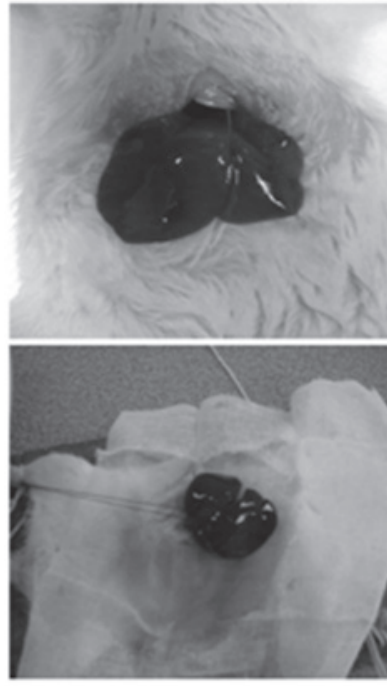

$\mathbf{8 3 . 4} \%$ hepatectomy

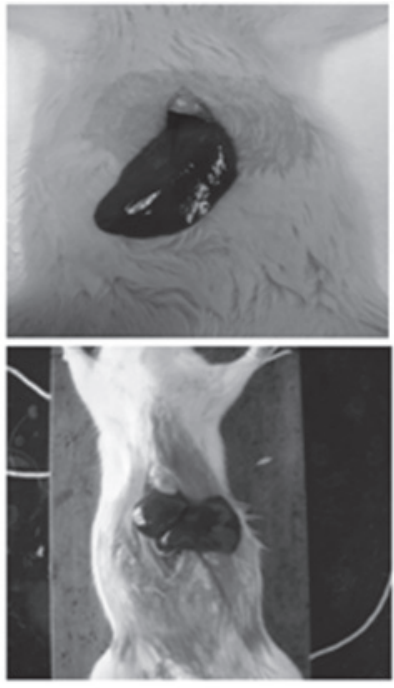

$73.1 \%$ hepatectomy
Figure 1. Images of PH rats. PH, partial hepatectomy.

fluorescence. Replacement of the primary antibody with PE-labeled IgG served as a negative control.

Western blot analysis. Rat liver tissue was homogenized (TissueRuptor; Qiagen, Hilden, Germany). Proteins were lyzed with lysis buffer containing $25 \mathrm{mM}$ Tris- $\mathrm{HCl}$ (pH 7.6), $150 \mathrm{mM} \mathrm{NaCl}, 1 \% \mathrm{NP}-40,1 \%$ sodium deoxycholate, $0.1 \%$ SDS, $1 \mathrm{mM}$ PMSF and protease and phosphatase inhibitor cocktails (all from Sigma-Aldrich), as described previously (19). Proteins were separated by SDS-PAGE and transferred to a PVDF membrane (Bio-Rad, Hercules, CA, USA) using standard techniques. Antibodies used for immunoblotting were as follows: CK-18, AFP and $\beta$-catenin, and horseradish peroxidase-conjugated $\operatorname{IgG}$ secondary antibodies (all Santa Cruz Biotechnology, Inc.). An ECL plus western blotting detection kit (Amersham Biosciences, Piscataway, NJ, USA) was used for development of the membrane.

Statistical analysis. All results are expressed as the mean \pm SD. Statistical differences were determined by Student's t-test. $\mathrm{P}<0.05$ was considered to indicate a statistically significant difference.

\section{Results}

Morphological features of freshly isolated cells from hepatectomized rats. Hepatectomy in rat livers was performed at 83.4 and $73.1 \%$ (Fig. 1). Collagenase perfusion was used to extract and isolate hepatic cells. In the control group, the newly separated hepatic cells were observed to exhibit a round shape, homogeneous size and strong diffraction. The viability of freshly isolated cells was $>95 \%$, as estimated by their ability to exclude trypan blue (data not shown). Following culture for 4-6 h, phase-contrast microscopy revealed that cells attaching to the culture dishes were round in shape (Fig. 2). After culture for 7 days, cells were observed to grow individually and no colonies were noted. Parts of the cells gradually stretched, causing fusiform or spindle-shaped growth. At day 14, 


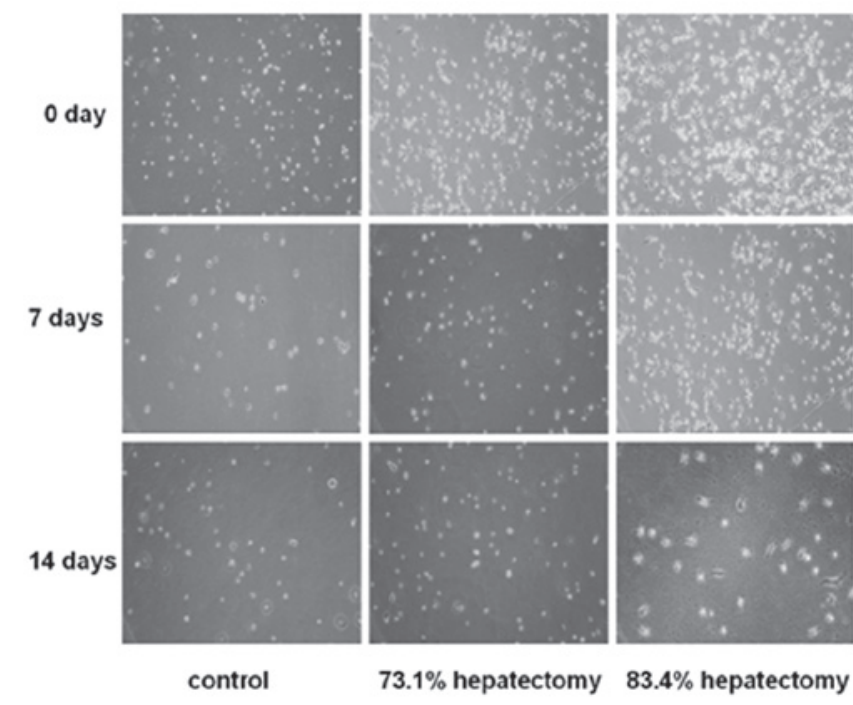

Figure 2. Histological features of rat livers following partial hepatectomy. Phase-contrast microscopy demonstrated the morphology of hepatic cells.
A
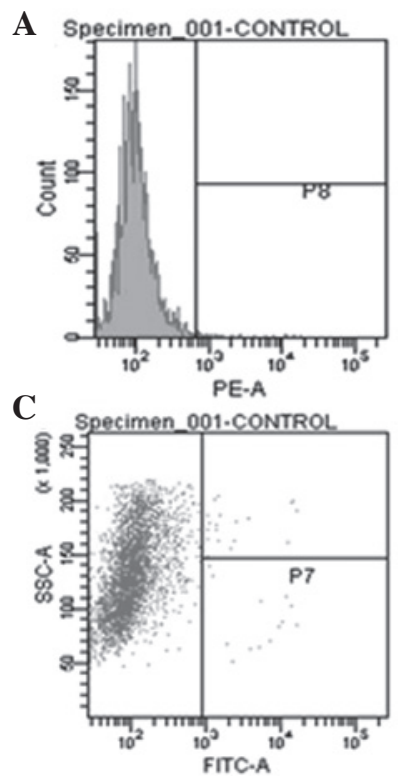

B

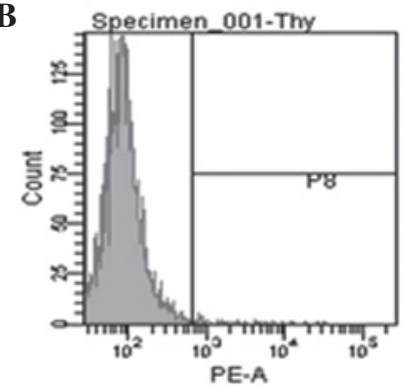

D

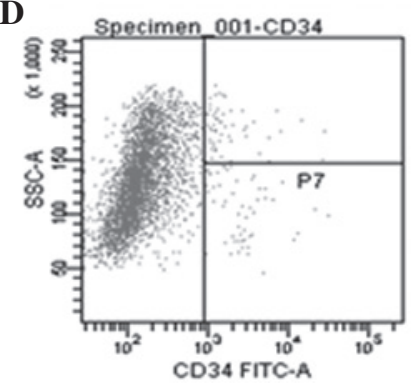

Figure 3. Phenotypic characteristics of oval cells indicated by flow cytometric analysis. (A) PE-labeled IgG secondary antibody, (B) Thy-1 primary antibody, (C) FITC-labeled IgG and (D) CD34. PE, phycoerythrin.

the majority of the cells were fibroblast-like (Fig. 2). In the $73.1 \%$ hepatectomy group, colony-like growth was observed following culture for 6 days and a number of cells were fused, indicative of hepatic stem cell proliferation (Fig. 2). In the $83.4 \%$ hepatectomy group, cells did not exhibit colony-like growth (Fig. 2).

Phenotypic characteristics of freshly isolated cells from hepatectomized rats. Next, the phenotypic characteristics of differentiated cells derived from isolated cells from $\mathrm{PH}$ rats were analyzed to confirm biochemical identity. Flow cytometry indicated that all the cells isolated from $\mathrm{PH}$ rats were positive for hepatic progenitor markers, CD-34 and Thy-1 (Fig.3). In $83.4 \%$ PH rats, a significant increase in
CD-34 and Thy-1 levels were observed compared with $73.1 \%$ $\mathrm{PH}$ rats.

In addition, when phenotypic characteristics were compared at 0,7 and 14 days following 83.4\% PH surgery, cells isolated 7 days following $\mathrm{PH}$ were observed to express CD-34 and Thy-1 at higher levels than cells at 0 and 14 days. In addition, the effect of various durations of IV collagenase perfusion on CD-34 and Thy-1 levels (Fig. 3) was analyzed. Perfusion of IV collagenase for $20 \mathrm{~min}$ resulted in a significant increase in CD-34 and Thy-1 levels, higher than that of 10 and 30 min collagenase perfusion.

Immunofluorescence analysis of proliferative oval cells. Hepatocyte differentiation was evaluated further by immunofluorescence analysis for AFP and CK-18 (markers of hepatocytes). Cells in the control group were negative for AFP and CK-18 (Fig. 4). By contrast, cells isolated from hepatectomized rats expressed AFP and CK-18, indicating that the cells had differentiated into hepatocyte-like cells. In the control group, expression of AFP and CK-18 was negative.

The effect of different $\mathrm{PH}$ procedures and duration of collagenase perfusion on differentiation was analyzed in vitro. As demonstrated in Fig. 4, immunofluorescence staining revealed that isolated cells on day 7 following 73.1 and $83.4 \% \mathrm{PH}$ surgery expressed AFP and CK-18 at high levels. Expression was highest in cells isolated from $83.4 \% \mathrm{PH}$ rats. Levels of AFP and CK-18 increased in cells isolated from $\mathrm{PH}$ rats perfused with collagenase for 20 min compared with 10 and 30 min perfusion. In addition, cells isolated 7 days following $\mathrm{PH}$ expressed AFP and CK-18 at higher levels than cells at 0 and 14 days (data not shown).

Analysis of AFP protein expression by western blot analysis. To further evaluate the phenotypic properties of differentiated cells, the expression of differentiation marker, AFP, was analyzed by western blot analysis in $83.4 \% \mathrm{PH}$ rats. Differentiated cells were observed to express AFP protein at high levels (Fig. 5). These results further indicated that oval cells were specified towards a hepatocyte lineage and that fully differentiated cells possess the genetic characteristics of mature hepatocytes following the isolation of cells from $\mathrm{PH}$ rats. In addition, consistent with results of immunofluorescence, cells isolated from rats 7 days following $\mathrm{PH}$ with collagenase perfusion for $20 \mathrm{~min}$ revealed stronger ATP expression.

\section{Discussion}

In recent years, there have been a number of advances in liver stem cell biology and studies have hypothesized that fetal liver stem cells (hepatoblasts) and adult liver stem cells (oval cells) may be useful for the generation of primary hepatocytes. These hepatic progenitors have the potential to give rise to hepatocytes or cholangiocytes (20-22). However, it has also been demonstrated that the number of hepatic progenitor cells in tissues are low, leading to difficulties in isolation, purification and expansion for large-scale expansion (23).

A large number of growth factors regulate cell proliferation and differentiation. Oh et al (24) previously reported that HGF promotes hepatic stem cell differentiation into hepatic cells in vitro. Fiegel et al (25) reported that $\mathrm{CD} 34^{+}$bone 

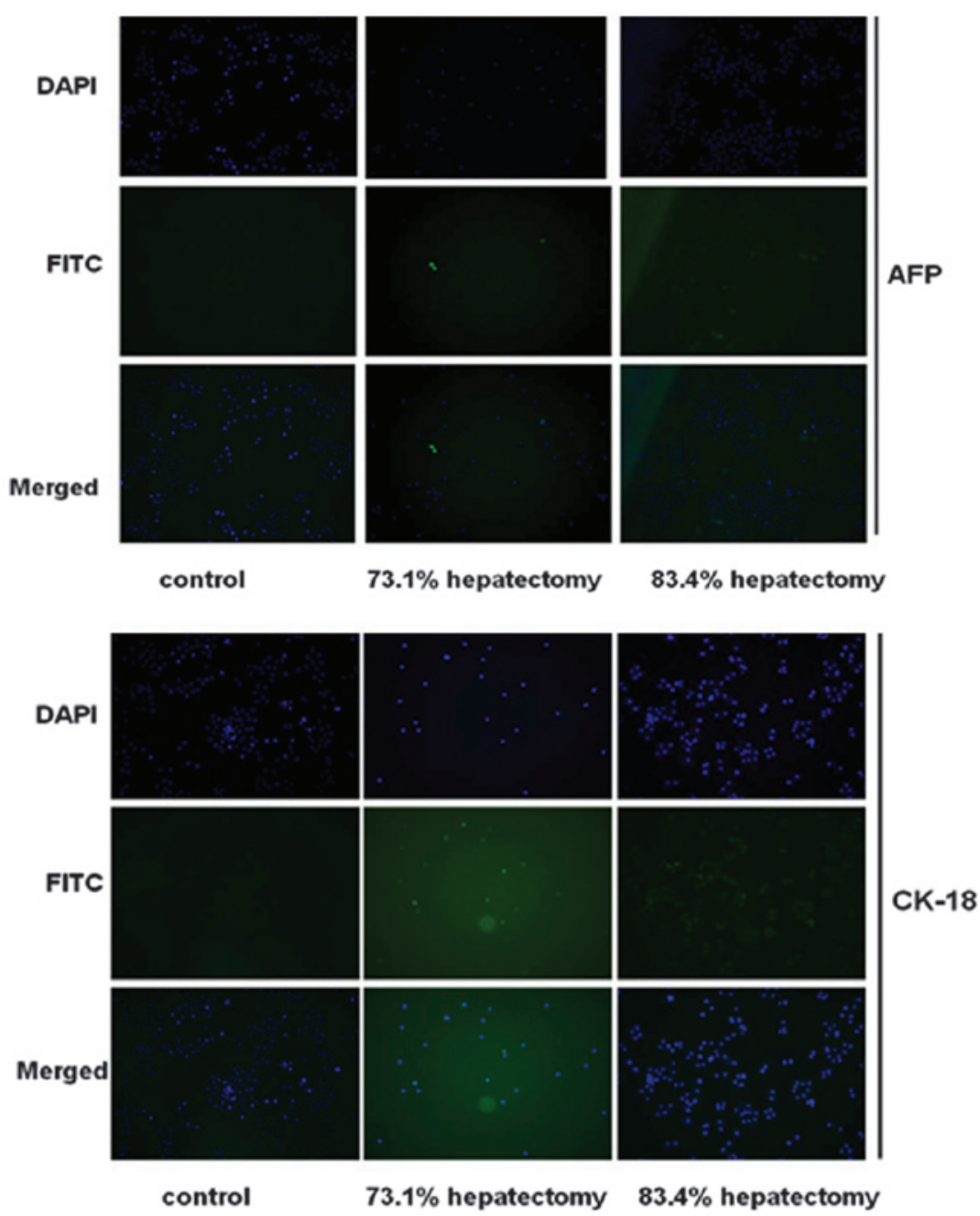

Figure 4. Characterization of the phenotypes of rat oval cells stained by immunofluorescence analysis. Immunofluorescence revealed the expression of AFP and CK-18 in oval cells following culture for 7 days. AFP, $\alpha$-1-fetoprotein; CK-18, cytokeratin 18.

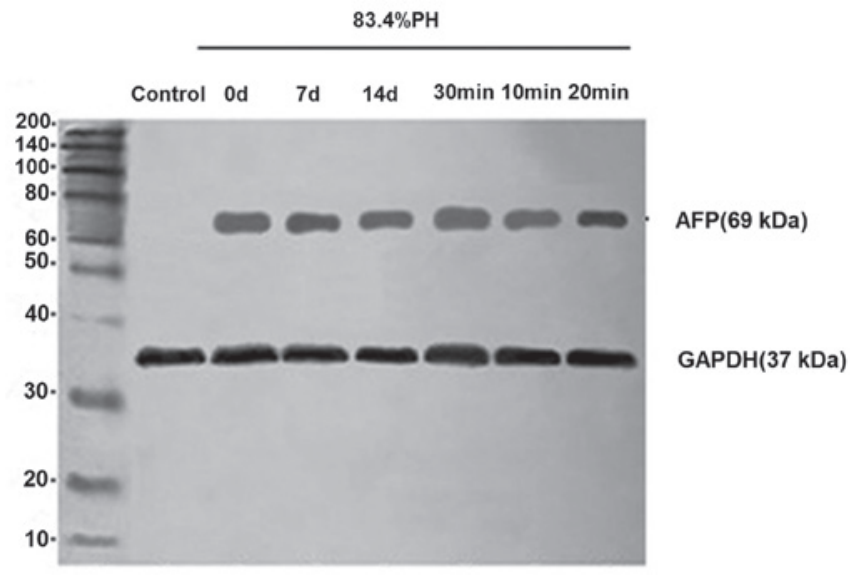

Figure 5. Western blot analysis of AFP protein expression. Blots presented are representative of typical results. GAPDH was applied to determine equal loading. AFP, $\alpha$-1-fetoprotein.

marrow hematopoietic stem cells express specific hepatic cell markers, including AFP and CK-18, when HGF is added to the culture medium. Additional studies demonstrated that stem cells originating from the liver are able to be differentiated into hepatocyte-like cells under HGF and epidermal growth factor (EGF) induction $(25,26)$. To date, HGF, FGF, EGF and transforming growth factor have been extensively applied in stem cell studies worldwide $(28,29)$.

Jang et al (30) found that damaged hepatic cells excrete specific factors when co-cultured with purified hematopoietic stem cells, inducing stem cells to differentiate into hepatocyte-like cells expressing hepatoid cells markers, including CK-18 and hepatocyte nuclear factor-3 $\beta$ (27). The ability of a number of factors to induce multipotent adult progenitor cell (MAPC) differentiation into functional hepatocyte-like cells was analyzed and optimal differentiation was observed when cells were cultured with FGF-4 and HGF. Human, mouse and rat MAPCs cultured with FGF-4 and HGF differentiated into epithelioid cells expressing hepatic cell markers, acquired functional characteristics of hepatocytes and maintained the accordant metabolic activity of humans (27). Ruhnke et al (31) reported that peripheral blood monocytes cultured with M-CSF and IL-3 expressed the hematopoietic stem cell marker, CD90, and monocyte marker, CD14, and then differentiated into hepatocyte-like (NeoHap) cells following induction by FGF-4 and HGF. The NeoHep cells resembled primary human hepatocytes with regard to morphology, expression of hepatocyte 
markers, various secretory and metabolic functions and drug detoxification activities. Following transplantation of NeoHep cells into the liver of severe combined immunodeficiency disease/non-obese diabetic mice, neohepatocytes integrated well into the liver tissue and revealed a morphology and albumin expression level similar to that of primary human hepatocytes transplanted under identical conditions (32).

In this context, to optimize hepatocyte formation, we first induced hepatic stem cell proliferation by $\mathrm{PH}$, and the liver was removed 0, 7 and 14 days following $\mathrm{PH}$. To obtain viable cells from the liver, two-step collagenase perfusion was performed. The first step consists of an isotonic buffer to flush blood cells and platelets from the vasculature. The second perfusate contained collagenase, which digests the extracellular matrix, allowing for the collection of a single cell suspension suitable for the isolation of discrete cell populations. IV collagenase was perfused for 10,20 or $30 \mathrm{~min}$.

Next, $5 \mu \mathrm{g} / 1 \mathrm{M}-\mathrm{CSF}, 0.4 \mu \mathrm{g} / 1 \mathrm{IL}-3$ and $140 \mu \mathrm{mol} / 1$ $\beta$-mercaptoethanol was added to RPMI-1640 medium for 6 days, followed by the addition of $20 \mu \mathrm{g} / \mathrm{l} \mathrm{HGF}$ and $10 \mu \mathrm{g} / \mathrm{l}$ FGF-4. Cell morphology was analyzed and proteins levels were determined by immunochemistry and western blot analysis. The results revealed that putative hepatic stem cells (oval cells) differentiate in vitro into cells that are morphologically, phenotypically and functionally representative of hepatocytes via a 2 -step induction protocol. HGF and FGF-4 are likely to initiate a stable hepatic phenotype and are key to oval cell specification toward hepatocytes, as indicated by the observation that these substances induced oval cells to change into small hepatocytes with hepatic characteristics. These results further confirmed that HGF and FGF-4 are important for hepatocyte differentiation.

Hematopoietic markers, including CD34 and Thy-1, although restricted to hematopoietic stem cells, have been used in a number of previous studies to identify and isolate hepatic progenitors $(33,34)$. The results of our study demonstrated that rat-derived stem cells differentiate in vitro into an endodermal cell type with hepatocyte phenotype. Hepatectomy is necessary to trigger $\mathrm{CD} 34^{+}$stem cells. The CD34 and Thy- 1 contents of $83.4 \% \mathrm{PH}$ cells were higher than that of $73.1 \% \mathrm{PH}$ cells. However, in the control group, cells were negative for CD34 and Thy-1, indicating that the difference of percentage in $\mathrm{PH}$ had an effect on the stem cell quantity. By contrast, differences in the isolation times following surgery were found to be associated with stem cell generation. At day 0 , no expression of CD34 and Thy-1 was observed, as the sorted cells were immature. Over time, the expression of CD34 and Thy-1 increased as the cells underwent maturation, with higher expression of CD34 and Thy-1 observed at day 7. However, on day 14, CD34 and Thy-1 expression began to decrease.

The expression of CD34 and Thy-1 was also analyzed under various durations of collagenase perfusion. Following 10 min perfusion, cells exhibited a polygonal or circle appearance and were negative for the hepatic stem cell markers, CD34 and Thy-1. By contrast, after 20 min perfusion, cells exhibited a stretched fibroblast-like appearance and expressed hepatic markers. However, the expression of CD34 and Thy-1 decreased following perfusion for $30 \mathrm{~min}$. These results indicated that the optimal conditions for generation of hepatic cells following $\mathrm{PH}$ include $83.4 \% \mathrm{PH}$ in rats followed by cell isolation at 7 days using perfusion for $20 \mathrm{~min}$. Long-term collagenase perfusion may inhibit stem cell formation.

Following cell culture in medium containing HGF and FGF-4, cells were characterized by the presence of hepatic markers, including AFP and CK-18. The expression of AFP and CK-18 was highest in cells isolated under perfusion for $20 \mathrm{~min}$ at day 7 following $\mathrm{PH}$, indicating that the optimal differentiation of hepatic stem cells to CK-18- and AFP-positive cells is observed in stem cells isolated from $83.4 \% \mathrm{PH}$ rats (7 days following surgery) perfused with IV collagenase for $20 \mathrm{~min}$.

In conclusion, results of the current study indicate that cells from $\mathrm{PH}$ were able to proliferate and differentiate into cells of the hepatic lineage. Differences in the isolation times following surgery and duration of perfusion were observed to affect stem cell generation and differentiation. The establishment of an in vitro protocol for the optimization of hepatic stem cell culture as described in this study is likely to be useful for the development of in vitro techniques for liver tissue or organ culture.

\section{References}

1. Kim WR, Therneau TM, Benson JT, et al: Deaths on the liver transplant waiting list: an analysis of competing risks. Hepatology 43: 345-351, 2006.

2. Duan BW, Lu SC, Wang ML, et al: Liver transplantation in acuteon-chronic liver failure patients with high model for end-stage liver disease (MELD) scores: a single center experience of 100 consecutive cases. J Surg Res 183: 936-943, 2013.

3. Verfaillie CM, Pera MF and Lansdorp PM: Stem cells: hype and reality. Hematology Am Soc Hematol Educ Program 2002: 369-391, 2002.

4. Fiegel HC, Lange C, Kneser U, et al: Fetal and adult liver stem cells for liver regeneration and tissue engineering. J Cell Mol Med 10: 577-587, 2006.

5. Alison MR, Choong C and Lim S: Application of liver stem cells for cell therapy. Semin Cell Dev Biol 18: 819-826, 2007.

6. Wilson JW and Leduc EH: Role of cholangioles in restoration of the liver of the mouse after dietary injury. J Pathol Bacteriol 76: 441-449, 1958.

7. Arber N, Zajicek G and Ariel I: The streaming liver. II Hepatocyte life history. Liver 8: 80-87, 1988.

8. Haruna Y, Saito K, Spaulding S, Nalesnik MA and Gerber MA: Identification of bipotential progenitor cells in human liver development. Hepatology 23: 476-481, 1996.

9. Petersen BE, Bowen WC, Patrene KD, et al: Bone marrow as a potential source of hepatic oval cells. Science 284: 1168-1170, 1999.

10. Wang X, Foster M, Al-Dhalimy M, et al: The origin and liver repopulating capacity of murine oval cells. Proc Natl Acad Sci USA 100 (Suppl 1): 11881-11888, 2003.

11. Li J, Li M, Niu B and Gong J: Therapeutic potential of stem cell in liver regeneration. Front Med 5: 26-32, 2011.

12. Takami T, Terai S and Sakaida I: Stem cell therapy in chronic liver disease. Curr Opin Gastroenterol 28: 203-208, 2012.

13. Russo FP and Parola M: Stem and progenitor cells in liver regeneration and repair. Cytotherapy 13: 135-144, 2011.

14. He ZP, Tan WQ, Tang YF, Zhang HJ and Feng MF: Activation, isolation, identification and in vitro proliferation of oval cells from adult rat livers. Cell Prolif 37: 177-187, 2004.

15. Colletti LM, Green M, Burdick MD, Kunkel SL and Strieter RM: Proliferative effects of CXC chemokines in rat hepatocytes in vitro and in vivo. Shock 10: 248-257, 1998.

16. Higgins GM and Anderson RM: Restoration of the liver of the white rat following partial surgical removal. Arch Pathol 12: 186-202, 1931.

17. Shupe TD, Piscaglia AC, Oh SH, Gasbarrini A and Petersen BE: Isolation and characterization of hepatic stem cells, or 'oval cells', from rat livers. Methods Mol Biol 482: 387-405, 2009.

18. Pack R, Heck R, Dienes HP, Oesch F and Steinberg P: Isolation, biochemical characterization, long-term culture and phenotype modulation of oval cells from carcinogen-fed rats. Exp Cell Res 204: 198-209, 1993. 
19. Bussolati B, Deambrosis I, Russo S, et al: Altered angiogenesis and survival in humantumor-derived endothelial cells. FASEB J 17: 1159-1161, 2003.

20. Herrera MB, Bruno S, Buttiglieri S, et al: Isolation and characterization of a stem cell population from adult human liver. Stem Cells 24: 2840-2850, 2006.

21. Lazaro CA, Rhim JA, Yamada Y and Fausto N: Generation of hepatocytes from oval cell precursors in culture. Cancer Res 58: $5514-5522,1998$

22. Rogler LE: Selective bipotential differentiation of mouse embryonic hepatoblasts in vitro. Am J Pathol 150: 591-602, 1997.

23. Czyz J, Wiese C, Rolletschek A, et al: Potential of embryonic and adult stem cells in vitro. Biol Chem 384: 1391-1409, 2003.

24. Oh SH, Miyazaki M, Kouchi H, et al: Hepatocyte growth factor induces differentiation of adult rat bone marrow cells into a hepatocyte lineage in vitro. Biochem Biophys Res Commun 279: 500-504, 2000.

25. Fiegel HC, Lioznov MV, Cortes-Dericks, et al: Liver-specific gene expression in cultured human hematopoietic stem cells. Stem Cells 21: 98-104, 2003

26. Miyazaki M, Akiyama I, Sakaguchi M, et al: Improved conditions to induce hepatocytes from rat bone marrow cells in culture. Biochem Biophys Res Commun 298: 24-30, 2002.

27. Schwartz RE, Reyes M, Koodie L, et al: Multipotent adult progenitor cells from bone marrow differentiate into functional hepatocyte like cells. J Clin Invest 109: 1291-1302, 2002.
28. Block GD, Locker J, Bowen WC, et al: Population expansion,clonal growth,and specific differentiation patterns in primary cultures of hepatocytes induced by HGF/SF, EGF and TGF alpha in a chemically defined (HGM) medium. J Cell Biol 132: 1133-1149, 1996.

29. Michalopoulos GK, Bowen WC, Mule K, et al: HGF-, EGF- and dexamethas-one-induced gene expression patterns during formation of tissue in hepatic organoid cultures. Gene Expr 11: 55-75, 2003.

30. Jang YY, Collector MI, Baylin SB, et al: Hematopoietic stem cells convert into liver cells within days without fusion. Nat Cell Biol 6: 532-539, 2004.

31. Ruhnke M, Nussler AK, Ungefroren H, et al: Human monocyte-derived neohepatocytes: a promising alternative to primary human hepatocytes for autologous cell therapy. Transplantation 79: 1097-1103, 2005.

32. Ruhnke M, Ungefroren H, Nussler AK, et al: Differentiation of in vitro-modified human peripheral blood monocytes into hepatocyte-like and pancreatic islet-like cells. Gastroenterology 128: 1774-1786, 2005

33. Terrace JD, Currie IS, Hay DC, et al: Progenitor cell characterization and location in the developing human liver. Stem Cells Dev 16: 771-778, 2007.

34. Petersen BE, Goff JP, Greenberger JS and Michalopoulos GK: Hepatic oval cells express the hematopoietic stem cell marker Thy-1 in the rat. Hepatology 27: 433-445, 1998. 